\title{
Article
}

\section{The context, influences and challenges for undergraduate nurse clinical education: Continuing the dialogue}

Forber, Jan, DiGiacomo, Michelle, Davidson, Patricia, Carter, Bernie and Jackson, Debra

Available at http://clok.uclan.ac.uk/12342/

Forber, Jan, DiGiacomo, Michelle, Davidson, Patricia, Carter, Bernie ORCID: 0000-0001-5226-9878 and Jackson, Debra (2015) The context, influences and challenges for undergraduate nurse clinical education: Continuing the dialogue. Nurse Education Today, 35 (11). pp. 1114-1118. ISSN 02606917

It is advisable to refer to the publisher's version if you intend to cite from the work. http://dx.doi.org/10.1016/j.nedt.2015.07.006

For more information about UCLan's research in this area go to http://www.uclan.ac.uk/researchgroups/ and search for <name of research Group>.

For information about Research generally at UCLan please go to http://www.uclan.ac.uk/research/

All outputs in CLoK are protected by Intellectual Property Rights law, including Copyright law. Copyright, IPR and Moral Rights for the works on this site are retained by the individual authors and/or other copyright owners. Terms and conditions for use of this material are defined in the policies page.

\section{CLoK}

Central Lancashire online Knowledge www.clok.uclan.ac.uk

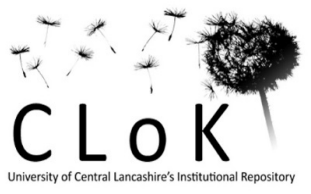




\section{Accepted Manuscript}

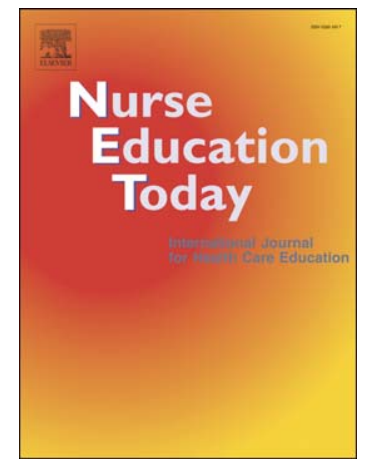

The context, influences and challenges for undergraduate nurse clinical education: Continuing the dialogue

Jan Forber, Michelle DiGiacomo, Patricia Davidson, Bernie Carter, Debra Jackson

PII:

S0260-6917(15)00276-2

DOI: $\quad$ doi: $10.1016 /$ j.nedt.2015.07.006

Reference: $\quad$ YNEDT 3006

To appear in: $\quad$ Nurse Education Today

Accepted date: 13 July 2015

Please cite this article as: Forber, Jan, DiGiacomo, Michelle, Davidson, Patricia, Carter, Bernie, Jackson, Debra, The context, influences and challenges for undergraduate nurse clinical education: Continuing the dialogue, Nurse Education Today (2015), doi: 10.1016/j.nedt.2015.07.006

This is a PDF file of an unedited manuscript that has been accepted for publication. As a service to our customers we are providing this early version of the manuscript. The manuscript will undergo copyediting, typesetting, and review of the resulting proof before it is published in its final form. Please note that during the production process errors may be discovered which could affect the content, and all legal disclaimers that apply to the journal pertain. 
Revision_UG_Clinical Education

\section{TITLE PAGE}

Title: THE CONTEXT, INFLUENCES AND CHALLENGES FOR UNDERGRADUATE NURSE CLINICAL EDUCATION: CONTINUING THE DIALOGUE.

Word count: XXXXX

\section{Authors:}

Forber, Jan. RN, BSc, MSc. PhD Candidate. Faculty of Health, University of Technology, Sydney, PO Box 123, Broadway, NSW 2007,Australia.

DiGiacomo, Michelle. BA, MSc (Health Sciences) PhD. Senior Research Fellow, Centre for Cardiovascular and Chronic Care. Faculty of Health, University of Technology, Sydney, PO Box 123, Broadway, NSW 2007, Australia.

Davidson, Patricia, M. PhD, RN. Dean, School of Nursing, John Hopkins University, Baltimore, US and Centre for Cardiovascular and Chronic Care, Faculty of Health, University of Technology Sydney. Johns Hopkins University, School of Nursing, 525 N. Wolfe Street, Baltimore, MD 21205, USA.

Carter, Bernie. PhD, BSc, SRN and RSCN. Professor of Children's Nursing, University of Central Lancashire, Preston, UK and Clinical Professor, University of Tasmania, Australia.

University of Central Lancashire, Fylde Road, Preston, Lancashire PR1 2HE, United Kingdom

Jackson, Debra. RN, PhD. Professor of Nursing, Faculty of Health \& Life Sciences, Oxford Brookes University and Professor, Nursing Research, Oxford University Hospitals NHS Trust.

Oxford Brookes University, Jack Straws Lane, Marston, Oxford OX3 OFL, United Kingdom

\section{Corresponding author:}

Jan Forber, Faculty of Health, University of Technology, Sydney, PO Box 123, Broadway, NSW 2007

Tel: $+61(0) 402670741$

Fax: +61 (0) 295144835

Email: Janet.Forber@student.uts.edu.au 
Revision_UG_Clinical Education

Acknowledgements: The first author is the recipient of an Australian Post Graduate Award however, there was no further source of funding for this review and no conflict of interest identified. 


\section{ABSTRACT:}

Introduction - Approaches to clinical education are highly diverse and becoming increasingly complex to sustain in complex milieu

Objective - To identify the influences and challenges of providing nurse clinical education in the undergraduate setting and to illustrate emerging solutions.

Method: A discursive exploration into the broad and varied body of evidence including peer reviewed and grey literature.

Discussion - Internationally, enabling undergraduate clinical learning opportunities faces a range of challenges. These can be illustrated under two broad themes: (1) Legacies from the past and the inherent features of nurse education and (2) Challenges of the present, including, population changes, workforce changes, and the disconnection between the health and education sectors. Responses to these challenges are triggering the emergence of novel approaches, such as collaborative models.

Conclusion(s) - Ongoing challenges in providing accessible, effective and quality clinical learning experiences are apparent.

Keywords: students, nursing, clinical education, innovation, education models 
Revision_UG_Clinical Education

\section{INTRODUCTION}

Undergraduate nurse clinical education is acknowledged for its role in socialising nursing students to professional practice and standards and nurturing the thinking, doing and emotional attributes needed to assimilate learning and integrate into the workforce (Willis 2012). Yet, this component of nursing programs can lack critical leadership and focus, be difficult to manage and is becoming more challenging, as demand for student placements intensifies (Smith, Corso \& Cobb 2010). Critical commentary in the literature (Allan 2010; Jackson \& Watson 2011), highlights concern that preparatory nurse education is facing emerging challenges from evolving healthcare policy, staff shortages and population changes, and these challenges are of local and international concern (Daly et al 2008).

In this current climate, stakeholders risk looking for a 'quick fix' to what Jackson et al. (2013, p. 150) aptly call the "Achilles' heel of health care professional curricula", and seek reactive and short-term solutions. Donnelly \& Wiechula (2012) caution that the nursing profession must seize the opportunity to engage in stimulating discussion on clinical education before political or financial constraints stifle creativity. To meet future demand for quality clinical experiences for students, requires clear leadership with a vision of change to drive sustainable and future proof innovation (Clinton \& Jackson 2009; Keighley 2013). 'Future proofing', according to Keighley (2013) is a process which determines future trends and generates forward thinking based on what is known today. The essence is that by future-proofing something - in this case clinical education - it will continue to be of value in the future.

\section{OBJECTIVE}

This paper sought to develop a snapshot roadmap to contextualise the barriers and facilitators to the clinical education of nurses. The overarching research questions were:

What are the inherent features in undergraduate nurse clinical education that impact its delivery?

What are the emergent challenges in the governance of undergraduate nurse clinical education? 
Revision_UG_Clinical Education

How are innovations being implemented to address these challenges?

\section{METHOD}

The literature was reviewed using electronic search engines (CINAHL, Medline and Scopus) and using the following search terms - Undergraduate[All Fields] AND ("nurses"[MeSH Terms] OR "nurses"[All Fields] OR "nurse"[All Fields]) AND clinical[All Fields] AND ("education"[Subheading] OR "education"[All Fields] OR "educational status"[MeSH Terms] OR ("educational"[All Fields] AND "status"[All Fields]) OR "educational status"[All Fields] OR "education"[All Fields] OR "education"[MeSH Terms]). The World Wide Web was searched for English language literature to generate findings on nursing clinical education. These findings were synthesised using a generalised inductive technique using the overarching research questions.

The findings are presented in a discursive style to act as a primer for debate, continued dialogue and foundation to inform future scholarship in this intricate area. The discourse is presented in three parts, beginning with understanding legacies of the past and the inherent features in clinical education that influence its provision. A summary of factors indicative of the contemporary challenges follows, relating to: influences on supply and demand; the disconnect between healthcare and education; healthcare reforms and changes to the nurse's role; and the determination of fitness for practice. Finally, examples of innovative approaches conceived for future undergraduate nurse clinical education are summarised.

\section{LEGACIES OF THE PAST}

Internationally, multiple approaches as to how the clinical component of undergraduate nurse education programs are conceptualized, described and delivered make this a challenging area for collective review. In many countries, including Australia, Canada, and the United Kingdom nurse education has evolved from the hospital-based apprentice training of the past to degree level preparation. Degree program curricula are frequently guided by education standards, issued by accrediting bodies, such as the UK's Nursing and Midwifery Council (NMC 2010) and the Australian Nursing and Midwifery Accreditation Council (ANMAC 2012). These standards guide the requirements for students to achieve the necessary beginning level competency for 
Revision_UG_Clinical Education

registration, yet provide scope for flexibility and differentiation in local program content. With reference to the Australian context, Walker (2009) questions this flexibility as a potential risk, allowing for variable curricula able to produce a variable 'product' - the nurse graduate.

Regardless of the ideological shift from 'training' to 'education' (Bradshaw \& Merriman 2008), and the 'model' of clinical education, features emanating from the hospital apprenticeship models still prevail. This is evident in the common term 'clinical placement' which Roxburgh, Conlon \& Banks (2012) suggest implies that learning can be contained within the boundaries of a physical location, specific team or time. As part of a rotational access model, students are allocated to various placements in different settings, with diverse patients and supervisors. The model may be driven by availability and competition rather than the educational needs of the curriculum or learner (Holland et al. 2010). This can result in disconnected experiences (Campbell 2008) with students unsure how particular settings meet their specified or personal learning objectives (Mannix et al 2006).

Historically, rotational models have centred on the acute care sector where high acuity, rapid patient turnover, specialization, patient safety and numbers of learners may not guarantee appropriate learning opportunities avail themselves. Lauder (2008) comments that acute care settings emphasise 'illness' and 'patients', thus promoting the medical model rather than person centred, social models of health. Continued reliance on the acute care setting will not adequately prepare students for primary healthcare or community based employment, growth areas within healthcare provision. Another common practice is for students to provide total patient care to increasing numbers of patients as they progress through their program of study. Benner et al (2010) caution that there is a misguided assumption that this makes students more 'work ready' on completion and they suggest that alternate ways for students to progress, develop and increase independence are needed.

The move to tertiary education conferred supernumerary status on students, giving rise to the need for models of student supervision. In their review, Budgen \& Gamroth (2008) identified 10 clinical (or practice) education models, which often emphasise the mode of student supervision, rather than an overarching approach to teaching and learning. A spectrum of differing models 
Revision_UG_Clinical Education

and definitions of student supervision has evolved with a variety of terms used, sometimes interchangeably, including 'supervising', 'mentoring', 'facilitating' and 'preceptoring'. As examples, mentoring utilises clinically based nurses - the nurse mentor, with student supervision part of the nurse's standard role (Jokelainen et al. 2011). Alternatively in the clinical facilitator models, registered nurses ( $\mathrm{RN}^{\prime} \mathrm{s}$ ) are employed by the higher education institution (HEI) to supervise students, typically in a 1:8 ratio and over several wards (Courtney-Pratt et al. 2012).

The preparation and governance of student supervisors, regardless of the model, also differs. In the UK, the Nursing and Midwifery Council's (NMC 2008) Standards to Support Learning and Assessment in Practice detail a formalised, nationwide structure. In contrast, with no formalised national structure in Australia, the need for greater consistency in supervisor preparation and governance has been identified (Andrews \& Ford 2013).

FurtheR variables are the numerical parameters of undergraduate clinical education. These include the total practice hours stipulated by governing bodies; the duration, number and type of placements or experiences; the range of shifts; and number and type of patients a student cares for. Illustrative of this is the disparity in student clinical practice hours within preparatory programs; the European Union requirement of 2300 hours, for example, contrasts with Australia's minimum of 800 hours (EU 2005/36, ANMAC 2012). The duration of clinical exposure, along with its organisation and the complex issue of assessment of competence are factors to consider when student exchange and, more significantly, potential mobility of the global nursing workforce are considered (Dobrowolska et al. 2015). This may be particularly pertinent to countries reliant on a migrant workforce to sustain the nursing workforce.

These facets exemplify the complexities and anomalies that intrinsically exist in undergraduate nurse clinical education. In addition, the provision of clinical learning experiences is also challenged by more contemporary issues such as healthcare, workforce and population changes. 
Revision_UG_Clinical Education

\section{CHALLENGES OF THE PRESENT}

Supply and Demand - The nursing workforce is aging, with the median nurse age, for example reported by the Australian Institute of Health and Welfare as 44.5 years and the Canadian Institute for Health Information stating 45.4 years (AIHW 2012; CIHI 2011). As this sector of the nurse workforce moves towards retirement, a looming void contributes to projected nursing workforce deficits in countries including Australia, the United Kingdom and US (NHWT 2009; Sherman, Chiang-Hanisko \& Koszalinski 2013). In addition, high rates of attrition, especially amongst early career nurses further compound predicted workforce shortfalls (Doiron, Hall \& Jones 2008). These deficits occur at a time of growing demand for healthcare services, driven by societal changes, such as the growing aged population, evident in many countries (European Commission 2012) and greater nursing involvement in aged care, primary and sub-acute care settings (ANMAC 2012; Smith, Spadoni and Proper 2013). Paradoxically, as the world faces increasing numbers of individuals with disability, the evident contraction in the availability of clinical sites, creates a challenge in achieving scale in workforce development.

A traditional strategy to boost supply is increased capacity in nursing programs (Sherman, Chiang-Hanisko \& Koszalinski 2013). Buerhaus et al (2013) also see large numbers of younger people entering nursing as key in delivering the growth in the nursing workforce over the period 2020-2030. The ramifications of this are demonstrated in Health Workforce Australia data (HWA 2013) which shows that 11,046 students commenced Australian undergraduate nursing programs in 2005, increasing to 16,328 in 2011 . This $48 \%$ increase in students, creates a substantial increased demand for quality clinical placements and impacts healthcare services and staff. Jackson \& Watson (2011) and Smith, Corso \& Cobb (2010) note how this contributes to a 'supply and demand' situation, increasing competition amongst providers of nurse education. With reported first year cohorts of 806 students (Salamonson et al. 2012) considerable local pressure is generated on healthcare to host clinical learning experiences for nursing students. Further, within these large cohorts diversity characteristics including age, English language proficiency and finances can negatively impact on clinical experiences and 
Revision_UG_Clinical Education

require attention to clinical placement design and delivery (Koch et al. 2014). Understandably, in this drive to increase 'quantity' it is debated whether sufficient attention has, will or can be given to the 'quality' of clinical education (Levett-Jones 2007; Roxburgh, Conlon \& Banks 2012).

Disconnection - The shift of nursing education into the tertiary sector has resulted in what Allan (2010) terms, an 'uncoupling' of health and education with a perceived lack of leadership for nurse education. O'Driscoll, Allan and Smith's (2010) case study of four UK health service trusts found that whilst ward managers had strategic responsibility for education and the clinical learning environment, they lacked a direct role in student learning. Responsibility for student supervision and education falls to the registered nurse who, focused on patient care delivery, can feel unprepared and unsupported in the supervisory role (O'Driscoll, Allan \& Smith 2010). Where the clinically based RN acts as the student supervisor (mentoring), issues with the lack of preparation, confidence, recognition, time and organisational support are potential barriers to effective supervision (Courtney-Pratt et al. 2012, Myall, Levett-Jones \& Lathlean 2008). Greater recognition of the role ward based $\mathrm{RN}$ supervisors play in students' development has been recommended, with managers supporting the $\mathrm{RN}^{\prime} \mathrm{s}$ preparation and development for the role, underpinned with effective communication channels (Myall, Levett-Jones \& Lathlean 2008).

In contrast, in models of student supervision where the education institution provides the student supervisor, for example clinical facilitator models, other issues arise. Here both the supervisor (clinical facilitator or 'faculty') and student are 'guests' in a facility, necessitating that the supervisor must develop alliances to identify learning opportunities and engage facility staff in student support (Dickson, Walker \& Bourgeois 2006). In this approach, the bedside RN continues to play a vital role guiding students when the facilitator is unavailable and CourtneyPratt et al. (2012) established that heavy workloads, time constraints and sheer numbers of students can affect these 'buddy' RN's ability to spend time with students.

Healthcare reform - Healthcare restructuring and reform has driven changes to the nurse's role with the increased prevalence of un-registered support roles, reducing the capacity of healthcare providers to host student clinical placements (Allan \& Smith 2009; Smith, Corso \& Cobb 2010). In the UK, Allen and Smith (2009) found the increase in Assistant in Nursing (AIN) 
Revision_UG_Clinical Education

positions, has resulted in the registered nurses becoming the prescriber of care rather than the provider of care. Subsequently, one consequence is that students may not perceive 'essential or basic care' as the role of the registered nurse. Hasson et al.'s (2013) semi-structured interviews with unregistered healthcare workers $(n=59)$, found student nurses worked alongside them to deliver patient care, due to limited RN availability. Interviewees revealed they were unofficially or informally involved in student education, teaching students basic clinical and non-clinical tasks. Similarly, Annear, Lea \& Robinson (2014) explored the potential for care workers in the growing aged care sector to act as mentors to student nurses. However, overcoming student's initial negative attitudes and demonstrating the links between fundamental care activities, such as hygiene, to wider nursing competencies needed to be addressed to better conceptualize these facilities for placements. As yet not fully explored within the literature, these non RN roles and less traditional placement areas require consideration in workforce projection and planning due to their impact on diversification, skill mix and subsequent capacity to supervise and assess students.

Determining 'fitness for practice' - Within the nursing profession, there is an all too common phrase, that new graduate nurses need to "hit the ground running" (Cross 2009: p. 57), indicative of a lingering perception that moving nurse education to degree based preparation, has resulted in new graduates who are not 'fit for practice nor purpose'. Bradshaw and Merriman (2008) lament the limited clinical skills of new graduates and the loss of fixed syllabuses with regimented skills testing to prescribed standards. However, the current high expectations and the focus on practical skills as a marker for competence upon registration are influenced by wider issues such as workforce shortages, skill mix changes and escalating clinical demands.

The desire for new nurses to fill a void may be indicative of the reality and demands of the contemporary workplace (Chernomas et al. 2010) rather than new nurses' lack of preparedness or short comings of nurse education (Wolff, Pesut \& Regan 2010). Holland et al.'s (2010) evaluation of the Fitness for Practice curriculum (UKCC 1999) in Scotland, found new graduates 
Revision_UG_Clinical Education

were 'fit for practice' on registration, though lacking in confidence; an important factor but distinct to lacking competence. In their research on perceptions of 'practice readiness', Wolff, Pesut and Regan (2010; p. 191) argue that the debate on the merit of the 'technically' (apprentice) prepared nurse versus the 'professionally' (tertiary education) prepared nurse, are "divisive and out-dated". They propose the debate move towards achieving appropriate new graduate transition into various healthcare settings, where a myriad of influences, including staff shortages and emerging technologies impact their integration into the workforce (Wolff, Pesut \& Regan 2010).

Nurse education and the competency debate are further fuelled by public opinion and media reaction, where sentimentality for the past, lack of insight into contemporary healthcare and romanticized nursing images are evident. Headlines in the UK media suggest that degree educated nurses are "too posh to wash" or "too clever to care" (Fawcett 2013) are myths dispelled by the Willis Commission (Willis 2012). When the Australian healthcare system was under scrutiny, Jackson and Daly (2008) presented a thought provoking snapshot of letters from Australian metropolitan newspapers, many critical of the university educated nurses, harping back to the "good" old days and unappreciative of a well-educated nurse workface.

The response to these contemporary challenges varies from the establishment of government agencies, for example Health Workforce Australia (HWA) to independent commissions, reporting the 'health' of pre-registration nursing education (Willis 2012). In addition, however, nurses are driving reforms to enhance the robustness of future solutions, as the following cases illuminate.

\section{IMPLEMENTING INNOVATION}

Addressing the 'uncoupling' of health and education, Dedicated Education Unit (DEU) and related clinical education models, promote collaboration between practice and education partners. Defined by Moscato et al. (2007, p.32), a DEU is a healthcare setting "developed into an optimal teaching/learning environment through the collaborative efforts of management, 
Revision_UG_Clinical Education

clinical faculty, and staff nurses", where all staff engage in student learning. Compared to standard models, Callaghan et al. (2009) found students in DEU's benefit from observing many nurses practice, engaging in team-based care and communicating within the multidisciplinary team. Recent studies continue to highlight benefits of this model. Moscato, Nishioka \& Coe (2013) identified their value in early identification of failing students. Mulready-Shick et al. (2013) found nursing students had a preference for DEU's over traditional placements with retention of skills such as teamwork and DEU's have been reported to support high quality learning experiences with strong mentoring relationships (Nishioka et al. 2014).

Another collaboration described by Nielsen et al. (2013), is the Oregon Consortium for Nursing Education (OCNE) model with nine education partners collaborating to re-design and diversify nurse education. The spectrum of clinical learning activities within the model can be orientated around a skill, a concept, or a case, building up to episodes of total integrated patient care. The reported advantages are sustained health-education collaboration and ability to effectively meeting student's needs via diverse yet complementary clinical learning activities appropriate to their level (Tanner, Gubrud-Howe \& Shores 2008). However, Ostrogorsky and Raber's (2014) evaluation of first year student experiences indicate the ongoing challenges to increase effectiveness and refinement faced by whole scale shift and redesign of clinical education.

The evaluation of a Hub and Spoke Model in Scotland, addresses Benner et al.'s (2010) observation that few clinical curricula allow students to follow patients over time and across healthcare settings (Roxburgh, Conlon \& Banks 2012). This model provides flexible, student focused, interconnected experiences, with students based in a main location (hub) with alternate locations (spokes) offering learning opportunities not available in the hub. Evaluation shows promise as an alternative to the more traditional compartmentalized, placement style experiences (Roxburgh, Conlon \& Banks 2012).

Austria, Baraki and Doig (2013) and Ruth-Sahd (2011) have looked at student dyads to create a community of learning. Students work in pairs with their assigned patient(s) and findings demonstrate enhanced student confidence, team work and decision making. Student dyads 
Revision_UG_Clinical Education

may increase capacity as fewer RN's and patients are required each day (Austria, Baraki and Doig 2013).

Finally, there is mounting interest and evaluation in replacing in-situ clinical hours with simulated practice experiences. Up to 300 hours (13\% of total hours) of clinical time in UK programs can be replaced by simulation learning activities (NMC 2010). In the US, the National Council of State Boards of Nursing's (NCSBN) Simulation study is evaluating the replacement of up to $50 \%$ of 'traditional' clinical hours with simulation (Kardong-Edgren et al. 2012). The findings of this large-scale, randomized, controlled study state that equivalent end-of-program educational outcomes were achieved when high-quality simulation experiences replaced up to half of the clinical hours and that graduates were prepared for clinical practice (Hayden et al 2014). Achieving, high quality simulation experiences requires clear learning objectives to articulate with the curriculum, sufficient high quality simulation resources including adequately prepared staff, and debriefing to facilitate learning (Arthur, Levett-Jones \& Kable 2013). As Berragan (2011) states simulation provides a safe environment for the development of clinical skills but must connect with actual clinical practice to be effective.

The diversification of healthcare systems, population changes, changing profile of the student body and budget considerations will continue to challenge how clinical experiences are designed and developed. Innovative, future aware, novel, and flexible approaches that maximise use of resources and learning opportunities are necessary to ensure students engage in learning and emerge ready for practice.

\section{CONCLUSION}

This is a pivotal time for the future of the practice based, clinical experience component of undergraduate nursing programs. The notion of going 'back to the future' is not a valid option. In many countries, healthcare, indeed society and public expectation have changed and for the nursing profession continue to do 'more of the same' is unsustainable and unlikely to meet stakeholder's needs. 
Revision_UG_Clinical Education

Strategically, leaders in health care education need to be attentive to the impact their engagement in decision making, policy development and governance has on the undergraduate education and preparation of the future workforce. Finding ways to ensure the curricula, and crucially the clinical component, reflects the needs of all stakeholders, including students, and meets the evolving professional and societal needs both in the present and for the future, requires continued critical debate. 
Revision_UG_Clinical Education

\section{REFERENCES}

AlHW 2012, Nursing and midwifery workforce 2011. National health workforce series no. 2. , Australian Institute of Health and Welfare, Canberra, Cat. no. HWL 48. .

Allan, H.T. 2010, 'The perils facing nurse education: A call for leadership for learning', Nurse Education Today, vol. 30, pp. 209-11.

Allan, H.T. \& Smith, P.A. 2009, 'How student nurses' supernumerary status affects the way they think about nursing: a qualitative study', Nursing Times, vol. 105, no. 43, pp. 10-3.

Andrews, C.E. \& Ford, K. 2013, 'Clinical facilitator learning and development needs: Exploring the why, what and how', Nurse Education in Practice, vol. 13, no. 5, pp. 413-7.

ANMAC 2012, Registered Nurse: Accreditation Standards 2012, Australian Nursing and Midwifery Accreditation Council.

Annear, M., Lea, E. \& Robinson, A. 2014, 'Are care workers appropriate mentors for nursing students in residential aged care?', BMC Nursing, vol. 13, no. 1, pp. 1-16.

Arthur, C., Levett-Jones, T. \& Kable, A. 2013, 'Quality indicators for the design and implementation of simulation experiences: A Delphi study', Nurse Education Today, vol. 33, no. 11, pp. 1357-61.

Austria, M.J., Baraki, K. \& Doig, A.K. 2013, 'Collaborative Learning Using Nursing Student Dyads in the Clinical Setting', International Journal of Nursing Education Scholarship, vol. 10, no. 1, pp. 1-8.

Benner, P., Sutphen, M., Leonard, V. \& Day, L. 2010, Educating nurses. A call for radical transformation, Jossey-Bass, San Francisco.

Berragan, L. 2011, 'Simulation: An effective pedagogical approach for nursing?', Nurse Education Today, vol. 31, no. 7, pp. 660-3.

Bradshaw, A. \& Merriman, C. 2008, 'Nursing competence 10 years on: fit for practice and purpose yet?', Journal of Clinical Nursing, vol. 17, no. 10, pp. 1263-9.

Budgen, C. \& Gamroth, L. 2008, 'An overview of practice education models', Nurse Education Today, vol. 28, pp. 273-83.

Buerhaus, P.I., Auerbach, D.I., Staiger, D.O. \& Muench, U. 2013, 'Projections of the Long-Term Growth of the Registered Nurse Workforce: A Regional Analysis', Nursing Economic\$, vol. 31, no. 1, pp. 137.

Callaghan, D., Watts, W.E., McCullough, D.L., Moreau, J.T., Little, M.A., Gamroth, L.M. \& Durnford, K.L. 2009, 'The experience of two practice education models: collaborative learning unit and preceptorship', Nurse Education in Practice, vol. 9, no. 4, pp. 244-52.

Campbell, J. 2008, A literature/evidence review: exploration on new models and approaches to providing practice placements in mental health branch programmes, NHS Education for Scotland, Edinburgh.

Chernomas, W.M., Care, W.D., McKenzie, J.L., Guse, L. \& Currie, J. 2010, '"Hit the ground running": perspectives of new nurses and nurse managers on role transition and integration of new graduates', Canadian Journal of Nursing Leadership, vol. 22, no. 4, pp. 70-86.

CIHI 2011, Regulated Nurses: Canadian Trends, 2006 to 2010, Canadian Institute for Health Information.

Clinton, M. \& Jackson, D. 2009, 'Prologue: challenges in nurse education: a shared international perspective', Contemporary Nurse: A Journal for the Australian Nursing Profession, vol. 32, no. 12, pp. 6-8.

Courtney-Pratt, H., FitzGerald, M., Ford, K., Marsden, K. \& Marlow, A. 2012, 'Quality clinical placements for undergraduate nursing students: a cross-sectional survey of undergraduates and supervising nurses', Journal of Advanced Nursing, vol. 68, no. 6, pp. 1380-90. 
Revision_UG_Clinical Education

Cross, W. 2009, 'Tilting at windmills: a look at policy and workforce drivers that influence contemporary nurse education in Australia', Contemporary Nurse: A Journal for the Australian Nursing Profession, vol. 32, no. 1-2, pp. 55-8.

Daly, J., Macleod Clark, J., Lancaster, J., Orchard, C. \& Bednash, G. 2008, 'The Global Alliance for Nursing Education and Scholarship: Delivering a vision for nursing education', International Journal of Nursing Studies, vol. 45, no. 8, pp. 1115-7.

Dickson, C., Walker, J. \& Bourgeois, S. 2006, 'Facilitating undergraduate nurses clinical practicum: The lived experience of clinical facilitators', Nurse Education Today, vol. 26, no. 5, pp. 416-22.

Dobrowolska, B., McGonagle, I., Jackson, C., Kane, R., Cabrera, E., Cooney-Miner, D., Di Cara, V., Pajnkihar, M., Prlić, N., Sigurdardottir, A.K., Kekuš, D., Wells, J. \& Palese, A. 2015, 'Clinical practice models in nursing education: implication for students' mobility', International Nursing Review, vol. 62, no. 1, pp. 36-46.

Doiron, D., Hall, J. \& Jones, G. 2008, 'Is there a crisis in nursing retention in New South Wales? ', Australia \& New Zealand Health Policy (ANZHP) vol. Vol. 5 Special section p1-12. 12p, no. Special section pp. p1-12.

Donnelly, F. \& Wiechula, R. 2012, 'Clinical placement and case study methodology: A complex affair', Nurse Education Today, vol. 32, no. 8, pp. 873-7.

EU2005/36 2005, 'Directive 2005/36/EC of the European Parliament and of the Council of 7 September 2005 on the recognition of professional qualifications. ', Official Journal of the European Union, vol. L 255:22-142.

European Commission, 2012, The 2012 Ageing Report: Economic and budgetary projections for the EU27 Member States (2010-2060). Available at: http://ec.europa.eu/economy_finance/publications/european_economy/2012/pdf/ee-20122_en.pdf, accessed 12 June 20152012.

Fawcett, K. 2013, What future for Nursing and Nurses?, 2020 Health.org, London.

Hasson, F., McKenna, H.P. \& Keeney, S. 2013, 'Perceptions of the unregistered healthcare worker's role in pre-registration student nurses' clinical training', Journal of Advanced Nursing, vol. 69, no. 7, pp. 1618-29.

Hayden, J. 2011, 'A National Survey of Simulation Prevalence and Use as Clinical Replacement: Results from Phase I of the NCSBN Simulation Study', Clinical Simulation in Nursing, vol. 7, no. 6, pp. e254-e6.

Holland, K., Roxburgh, M., Johnson, M., Topping, K., Watson, R., Lauder, W. \& Porter, M. 2010, 'Fitness for practice in nursing and midwifery education in Scotland, United Kingdom', Journal of Clinical Nursing, vol. 19, no. 3-4, pp. 461-9.

HWA 2013, Australia's Health Workforce Series - Nurses in Focus, Health Workforce Australia, Adelaide.

JJackson, D. \& Daly, J. 2008, 'Nursing and pre-registration nursing education under the spotlight again', Collegian, vol. 15, no. 1, pp. 1-2.

Jackson, D., Daly, J., Mannix, J., Potgieter, I. \& Cleary, M. 2013, 'An overview of data-based papers on undergraduate nurse education recently published in Contemporary Nurse: Progress, challenges and the need for a strategic agenda', Contemporary Nurse, vol. 45, no. 2, pp. 146-51.

Jackson, D. \& Watson, R. 2011, 'Workplace learning: A continuing concern in nurse education', Contemporary Nurse, vol. 38, no. 1-2, pp. 3-5.

Jokelainen, M., Turunen, H., Tossavainen, K., Jamookeeah, D. \& Coco, K. 2011, 'A systematic review of mentoring nursing students in clinical placements', Journal of Clinical Nursing, vol. 20, no. 19/20, pp. 2854-67.

Kardong-Edgren, S., Willhaus, J., Bennett, D. \& Hayden, J. 2012, 'Results of the National Council of State Boards of Nursing National Simulation Survey: Part II', Clinical Simulation in Nursing, vol. 8, no. 4, pp. e117-23. 
Revision_UG_Clinical Education

Keighley, T. 2013, 'Future Proofing Nursing Education', paper presented to the In K. MacMillan (Ed.), Proceedings of a think tank on the future of undergraduate nursing education in Canada (pp.5563). Halifax: Dalhousie University School of Nursing, Canada, Halifax: Dalhousie University School of Nursing.

Koch, J., Everett, B., Phillips, J. \& Davidson, P.M. 2014, 'Diversity characteristics and the experiences of nursing students during clinical placements: A qualitative study of student, faculty and supervisors' views', Contemporary Nurse: A Journal for the Australian Nursing Profession, vol. 49, pp. 15-26.

Lauder, W. 2008, The Report of the Evaluation of Fitness For Practice Pre-Registration Nursing and Midwifery Curricula Project, NHS Education for Scotland.

Levett-Jones, T. 2007, 'Belongingness: a pivotal precursor to optimising the learning of nursing students in the clinical environment', Doctor of Philosophy thesis, University of Newcastle, Unpublished Thesis.

Mannix, J., Faga, P., Beale, B. \& Jackson, D. 2006, 'Towards sustainable models for clinical education in nursing: an on-going conversation', Nurse Education in Practice, vol. 6, no. 1, pp. 3-11.

Moscato, S.R., Miller, J., Logsdon, K., Weinberg, S. \& Chorpenning, L. 2007, 'Dedicated education unit: an innovative clinical partner education model', Nursing Outlook, vol. 55, no. 1, pp. 31-7.

Moscato, S.R., Nishioka, V.M. \& Coe, M.T. 2013, 'Dedicated Education Unit: Implementing an Innovation in Replication Sites', Journal of Nursing Education, vol. 52, no. 5, pp. 259-67.

Mulready-Shick, J., Flanagan, K.M., Banister, G.E., Mylott, L. \& Curtin, L.J. 2013, 'Evaluating dedicated education units for clinical education quality', The Journal of Nursing Education, vol. 52, no. 11, pp. 606-14.

Myall, M., Levett-Jones, T. \& Lathlean, J. 2008, 'Mentorship in contemporary practice: the experiences of nursing students and practice mentors', Journal of Clinical Nursing, vol. 17, no. 14, pp. 1834-42.

NHWT 2009, Health Workforce in Australia and Factors for Current Shortages, National Health Workforce Taskforce, Australia.

Nielsen, A.E., Noone, J., Voss, H. \& Mathews, L.R. 2013, 'Preparing nursing students for the future: An innovative approach to clinical education', Nurse Education in Practice, vol. 13, no. 4, pp. 301-9.

Nishioka, V.M., Coe, M.T., Hanita, M. \& Moscato, S.R. 2014, 'Dedicated education unit: student perspectives', Nursing Education Perspectives, vol. 35, no. 5, pp. 301-7.

NMC 2008, Standards to Support Learning and Assessment in Practice, NMC, London.

NMC 2010, Standards for pre-registration nursing education, NMC, London.

O'Driscoll, M.F., Allan, H.T. \& Smith, P.A. 2010, 'Still looking for leadership - Who is responsible for student nurses' learning in practice?', Nurse Education Today, vol. 30, no. 3, pp. 212-7.

Ostrogorsky, T.L. \& Raber, A.M. 2014, 'Experiences of First-Year Nursing Students During an Education Redesign: Findings from the Oregon Consortium for Nursing Education', Nursing Education Perspectives, vol. 35, no. 2, pp. 115-21.

Roxburgh, M., Conlon, M. \& Banks, D. 2012, 'Evaluating Hub and Spoke models of practice learning in Scotland, UK: A multiple case study approach', Nurse Education Today, vol. 32, no. 7, pp. 782-9.

Ruth-Sahd, L.A. 2011, 'Student nurse dyads create a community of learning: proposing a holistic clinical education theory', Journal of Advanced Nursing, vol. 67, no. 11, pp. 2445-54.

Salamonson, Y., Ramjan, L., Lombardo, L., Lanser, L.H., Fernandez, R. \& Griffiths, R. 2012, 'Diversity and demographic heterogeneity of Australian nursing students: a closer look', International Nursing Review, vol. 59, no. 1, pp. 59-65.

Sherman, R.O., Chiang-Hanisko, L. \& Koszalinski, R. 2013, 'The ageing nursing workforce: a global challenge', Journal of Nursing Management, vol. 21, no. 7, pp. 899-902.

Smith, P.M., Corso, L.N. \& Cobb, N. 2010, 'The perennial struggle to find clinical placement opportunities: A Canadian national survey', Nurse Education Today, vol. 30, no. 8, pp. 798-803. 
Revision_UG_Clinical Education

Smith, P.M., Spadoni, M.M. \& Proper, V.M. 2013, 'National survey of clinical placement settings across Canada for nursing and other healthcare professions-who's using what?', Nurse Education Today, vol. 33, no. 11, pp. 1329-36.

Tanner, C.A., Gubrud-Howe, P. \& Shores, L. 2008, 'The Oregon Consortium for Nursing Education: a response to the nursing shortage', Policy, Politics \& Nursing Practice, vol. 9, no. 3, pp. 203-9.

UKCC 1999, Fitness for Practice: the UKCC Commission for Nursing and Midwifery Education, United Kingdom Central Council for Nursing, Midwifery and Health Visiting UKCC, London.

Walker, K. 2009, 'Curriculum in crisis, pedagogy in disrepair: A provocation', Contemporary Nurse: A Journal for the Australian Nursing Profession, vol. 32, no. 1-2, pp. 19-29.

Willis, P. 2012, Quality with Compassion: the future of nursing education, The Willis Commission, London, UK.

Wolff, A.C., Pesut, B. \& Regan, S. 2010, 'New graduate nurse practice readiness: Perspectives on the context shaping our understanding and expectations', Nurse Education Today, vol. 30, no. 2, pp. 187-91. 
Revision_UG_Clinical Education

\section{HIGHLIGHTS}

- The provision of quality clinical learning experiences for undergraduate nursing students is becoming increasingly challenging and complex.

- Some challenges stem from the move from nurse education from apprentice type models to degree level tertiary preparation and could be considered as legacies of the past.

- Contemporary challenges, linked to population, workforce and healthcare policy, are also evident.

- Innovative solutions to the provision of undergraduate nurse clinical education are emerging and offer insight into sustainable approaches for the future. 